\title{
P-QOL questionnaire in Thai version
}

\author{
Viroj Wiwanitkit
}

Received: 3 March 2010 /Accepted: 7 April 2010/Published online: 18 May 2010

(C) The International Urogynecological Association 2010

\section{Dear Editor,}

I read the report by Manchana et al. with great interest [1]. Manchana et al. reported on validation of the Prolapse Quality of Life (P-QOL) questionnaire in Thai version and concluded that "The Thai version of the P-QOL questionnaire is a valid, reliable, and simple instrument to assess the symptoms' severity and the quality of life in Thai-speaking patients with pelvic organ prolapse" [1]. There are some concerns in this work. First, from a few selective tested subjects in this work, it is questionable that the questionnaire can be generalized for the general Thai population. Second, there is no report on questionnaire testing and reliability test by statistical means. Nevertheless, evidence of content validity, construct validity, concurrent validity, internal consistency reliability, and stability should be provided. Third, it is also questionable whether the demographic background of the subjects has any effect to the effectiveness of the questionnaire.

Conflicts of interest None.

\section{References}

1. Manchana T, Bunyavejchevin S (2010) Validation of the Prolapse Quality of Life (P-QOL) questionnaire in Thai version. Int Urogynecol J Pelvic Floor Dysfunct. doi:10.1007/s00192-0101107-3

A response to this letter can be found at doi:10.1007/s00192-0101182-5.

V. Wiwanitkit $(\bowtie)$

Wiwanitkit House,

Bangkhae,

10160 Bangkok, Thailand

e-mail: wviroj@yahoo.com 